\title{
Life history, population dynamics and production of eastern mosquitofish, Gambusia holbrooki (Pisces, Poeciliidae), in rice fields of the lower Mondego River Valley, western Portugal
}

\author{
João Alexandre Cabral *, João Carlos Marques \\ IMAR (Institute of Marine Research), Faculty of Sciences and Technology, Department of Zoology, University of Coimbra, 3000 Coimbra, Portugal. \\ * Corresponding author (fax: +351 39 23603; e-mail: jcabral@marao.utad.pt)
}

Received March 15, 1999; revised August 31, 1999; accepted September 20, 1999

\begin{abstract}
The introduced population of Gambusia holbrooki from the rice fields of the lower Mondego River Valley, Portugal, was studied for 15 months, relating their life cycle and population dynamics with its production, in order to assess the role of the species in the energy flow and secondary production in this type of agro-ecosystem. Two main annual cohorts (1995 and 1996 cohorts) were identified. The females outnumbered males and the average female/male-ratio was 4 . The inspection of ovary developmental stages of this viviparous fish, revealed that the most important reproductive period was between April and August. The first recruits were recorded in June and were present thereafter until October. Males from the parental cohort died before August, whereas parental females could survive until October. Mean adjusted fecundity (number of embryos divided by female standard length) peaked in July 1996 (0.95) and in June 1997 (1.05). Females reached greater sizes, had a higher growth rate and lived longer than males. Annual production was estimated at $3.101 \mathrm{~g} \cdot \mathrm{m}^{-2} \cdot \mathrm{year}^{-1}$ (ash-free dry weight, AFDW), the average biomass at $2.896 \mathrm{~g} \cdot \mathrm{m}^{-2}$ (AFDW), and the P/B ratio was 1.071 . A conjugation of life history, population dynamics, production and ecological traits (e.g. fast growth, reduced longevity, viviparity, high productivity, an intermediate position in food chain, and no special habitat requirements for reproduction) clearly show that the populations of $G$. holbrooki, introduced into rice fields all over the world, may play an important role in the structure and functioning of the biological communities of these important agro-ecosystems. (C) 1999 Éditions scientifiques et médicales Elsevier SAS
\end{abstract}

Mosquitofish / Gambusia holbrooki / Poeciliidae / growth / reproduction / population dynamics / production

\section{INTRODUCTION}

Eastern mosquitofish, Gambusia holbrooki (Girard) (Cyprinodontiformes: Poeciliidae), is native to the coastal region of the eastern United States, but has been widely introduced into warm temperate and tropical regions all over the world through mosquito control programmes $[10,21-23,28,33,38]$. The species was introduced to the Iberian peninsula in 1921 [1] and has invaded the lowest stream sections, wetlands and coastal lagoons [35]. This viviparous fish is well known for its consumption of insect larvae, zooplankton and other invertebrates $[5,8,11-13,24$, 25] but also as a threat to native fishes in habitats where mosquitofish have been introduced. Rupp [32] reported that the harmful consequences of Gambusia introductions ranged from eating the eggs of economi- cally desirable fishes to endangering rare indigenous species. Viviparity and a high reproductive effort may give such exotics an advantage over native oviparous species, because fry are larger, feed at birth, grow more quickly and become predators faster [32]. In Portugal, the most serious conservation problem for endemic fishes has been introductions of exotic species dating from the time of the Roman occupation of Iberia [3].

In the lower Mondego River Valley (western Portugal), the mosquitofish is very abundant, namely in rice fields (Cabral, unpubl. data). Rice culture is the most important agricultural activity in the world, occupying an enormous area $\left(150 \cdot 10^{6}\right.$ ha) [16]. Rice fields are complex ecological systems with a variety of plant and animal species [27]. In the lower Mondego River Valley, rice fields are linked by drainage and irrigation 


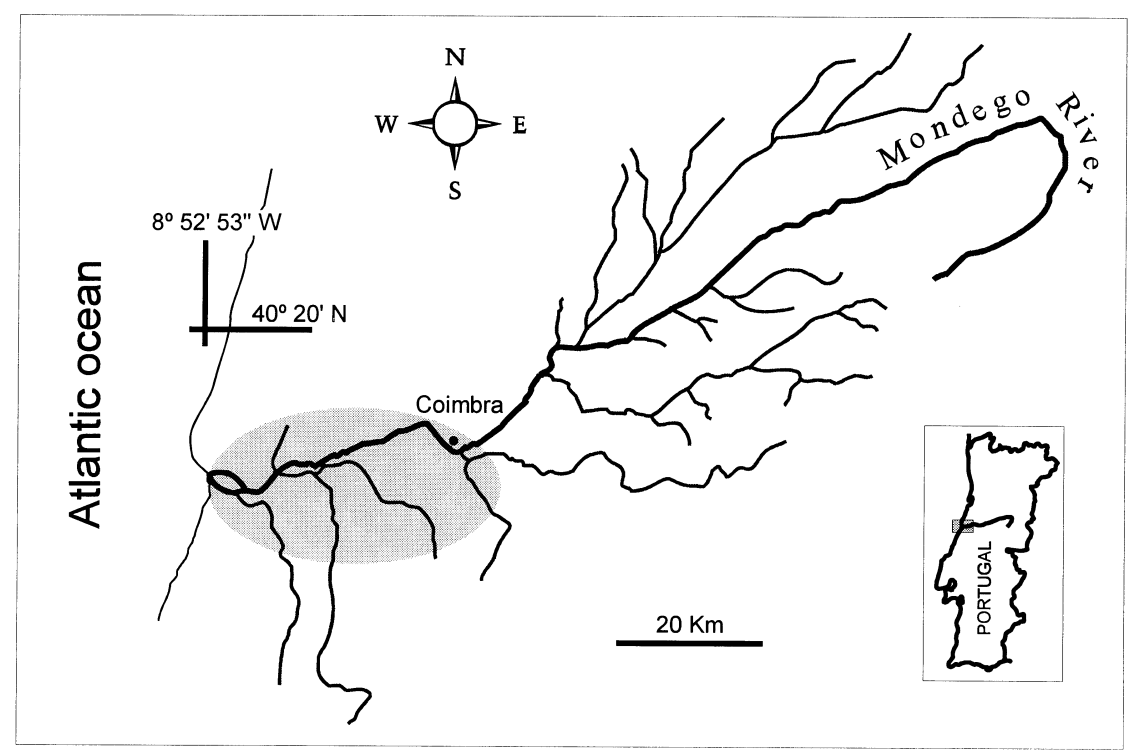

Figure 1. Location of the lower Mondego River Valley (shaded area).

channels spread across the whole valley with other ecosystems, such as rivers, streams and wetlands [4].

Mosquitofish is presently one of the most widely distributed species of freshwater fish in the world, and is believed to be the most widely disseminated natural predator in the history of biological control [6]. In the Iberian peninsula, there have been studies on the reproductive biology and population dynamics of $G$. holbrooki in rice fields $[14,18,19]$ and lagoons [15, 35], but its productivity has received little attention. This study addresses this information gap by relating life cycle and population dynamics of the mosquitofish with its production. The integration of this information with the existent knowledge of the relationships between mosquitofish and its main prey in rice fields of the lower Mondego River Valley [8], is an important requirement to assess the role of the species in the energy flow and secondary production in non-native rice fields.

\section{MATERIALS AND METHODS}

\subsection{Study site}

The lower Mondego River Valley (figure 1), in central Portugal $\left(40^{\circ} 10^{\prime} \mathrm{N}, 08^{\circ} 41^{\prime} \mathrm{W}\right)$, consists of approximately $15000 \mathrm{ha}$. The main agricultural crop is rice, occupying about $60 \%$ of the farmable area. Non-cultivated areas, such as swamps, appear in the periphery of the valley, and have characteristic wetland fauna and flora. Drainage channels are spread across the whole valley, constituting biological reservoirs for rice fields (rice paddies and irrigation channels) [4].

In the chosen study site, mosquitofish occur in rice paddies and irrigation channels. However, since rice fields are exposed to dramatic manipulation of the water level, the paddies are dry or have little water during much of the year, whereas the main irrigation channels always have enough water to support a population of mosquitofish. The sampling programme was therefore focused on irrigation channels.

\subsection{Field programme}

Sampling was carried out from April 1996 to June 1997, fortnightly during the most important mosquitofish reproduction period (April-July) and monthly in the remaining period. For each sample, mosquitofish were electrofished in three randomized areas confined by flexible nets (5-mm mesh size) transversally laid across the irrigation channel. A semi-portable generator supplied a rectified DC current (350-600 V). Sampling always took place between 10:00 and 13:00 hours, corresponding to the most active mosquitofish period [12]. Sampled areas ranged from 3 to $16 \mathrm{~m}^{2}$ and were shocked during a period of 30 to $40 \mathrm{~min}$, enough to catch virtually all the fish present in each area. Mosquitofish caught were immediately preserved in $4 \%$ buffered formalin, whereas other fishes were returned to the irrigation channel. 
Water temperature, conductivity, dissolved oxygen $\left(\mathrm{mg} \cdot \mathrm{L}^{-1}\right)$, and $\mathrm{pH}$, were measured in situ at each sampling location. Water volume was estimated from depth and width measurements in a 148.7-m long representative section of the irrigation channel, and then extrapolated for the entire channel.

\subsection{Laboratory procedures}

In the laboratory, the fish were washed, counted and preserved in $70 \%$ ethanol. All individuals were measured for standard length $(\mathrm{mm})$ and classified as: immature (normally $\leq 15 \mathrm{~mm}$ ) if sex could not be determined externally, adult males if a gonopodium was present, non-gravid females or gravid females. A total of 5003 fish were examined. All females were dissected. Ova and embryos were removed from the ovaries, measured (maximum diameter) with an ocular calibrated micrometer, counted, and assigned to one of five developmental stages: (1) opaque, white nonfertilized eggs about $100 \mu \mathrm{m}$ in diameter [34]; (2) intermediate between immature ova (partially yolked) and mature ova with a clear amber colour (complete complement of yolk but no embryonic structures visible) [29, 34]; (3) a stage from the primitive streak to the early embryo (eyes not fully formed; little dorsal pigmentation); (4) middle embryo (eyes fully formed; heavier pigmentation; moderate amount of yolk remaining); and (5) late embryo (little or no yolk remaining; ready for parturition) [29]. The females in developmental stage 2 or in older stages were considered as gravid females. Sex-ratios were calculated as the number of females per male.

For growth analysis, 168 individuals (males, females and immature) were measured for both total length (TL in $\mathrm{mm}$ ) and standard length (SL in $\mathrm{mm}$ ). This procedure permitted conversion of the maximum possible mosquitofish TL (males and females), described by Vondracek et al. [36] for G. affinis (a very similar species), into SL. The following regression equation for TL-SL conversion was determined: $\mathrm{SL}=-0.02+0.81 \mathrm{TL}\left(r^{2}=0.98, P<0.001\right)$.

Length-weight relationships were determined to estimate production. During the summer, the only period in which all size classes were present, 156 individuals were collected to provide a single regression equation for SL-AFDW (ash-free dry weight in g) conversion. The following equation was obtained: $\mathrm{AFDW}=1.56 \mathrm{E}^{-6} \times \mathrm{SL}^{3.24} \quad\left(r^{2}=0.96, \quad P<0.001\right)$. Specimens were dried in an oven for $48 \mathrm{~h}$ at $60{ }^{\circ} \mathrm{C}$ and weighted, and ignited in a muffle furnace for $8 \mathrm{~h}$ at $450{ }^{\circ} \mathrm{C}$ to obtain AFDW. Weight determinations were carried out with a $10^{-5} \mathrm{~g}$ precision.

\subsection{Data analysis}

Growth rates were deduced by tracking recognizable cohorts along size-frequency distributions (1-mm
SL classes) from successive sample dates. All fish born during the same reproductive period were assigned to the same cohort [15]. Mosquitofish length-frequency histograms, complemented with scale readings, allowed a visualization of the population structure throughout the year. Since there is genetically-based size polymorphism in Gambusia, the growth process is different for each sex. Female mosquitofish have indeterminant growth and may attain a size greater than $60 \mathrm{~mm}$ TL (approximately $50 \mathrm{~mm} \mathrm{SL}$ ), representing, therefore, a continuous range of growth from the first immature stages, whereas males tended to stop growing upon reaching maturity, approximately with $25 \mathrm{~mm}$ TL (20.2 mm SL) [36]. Therefore, we considered separately immature and females combined (with continuous growth) and males because population structure analysis becomes difficult if males are considered together with the remainder of the population. Since age determination by scale readings was inconclusive regarding birth dates $(>98 \%$ individuals belonged to the $0^{+}$age group, without 'annuli') and sizes often overlap, the 'breaks' between cohorts (after the appearance of the first recruits) were considered from the first inflexion-point between recognizable mode groups with biological sense. The monthly average and standard deviations of SL to cohorts detected were calculated, which established the annual growth pattern for each sex. Since growth rates are normally not constant through the year, seasonal variations were taken into consideration using a model proposed by Gaschütz et al. [20], where growth in length is expressed as:

$\mathrm{L}_{t}=\mathrm{L}_{\infty}\left\{1-\mathrm{e}^{-\left[\mathrm{kD}\left(t-t_{0}\right)+\mathrm{C}(\mathrm{kD} / 2 \pi) \sin 2 \pi\left(t-t_{\mathrm{s}}\right)\right]}\right\}^{1 / \mathrm{D}}$

where $\mathrm{L}_{t}$ is the length of the organism at a given moment $t ; \mathrm{L}_{\infty}$ the maximum possible length of the organism; $t$ the given instant; $t_{0}$ the instant when the organism would have a length equal to $0 ; t_{\mathrm{s}}$ the time interval between growth start (when $t=0$ ) and the first growth oscillation (growth is expressed by a sine curve with a 1-year period); $\mathrm{k}$ the intrinsic growth rate; $\mathrm{C}$ the parameter, the values of which can range from 0 to 1 , depending on the species; and $\mathrm{D}$ the parameter that expresses metabolic deviations from the Von Bertalanffy's $2 / 3$ rule (the metabolism of an organism is proportional to its weight by a $2 / 3$ power).

Size-frequency analysis also allowed an estimate of the density of each cohort at each sampling date. Daily mortality rate was estimated by the adjustment of a negative exponential curve to the densities of the cohort detected from the recruitment period, when it reached the maximum density value, to the period where all the individuals belonging to this cohort disappeared [4]. This adjustment $\left(y=\mathrm{a} \times 10^{-\mathrm{b} x}\right)$ was performed for both sexes, where $x$ and $y$ are time in 
days and density (individuals $\cdot \mathrm{m}^{-2}$ ), respectively, and a and $b$ are parameters to be determined. Since daily mortality rate $(\mathrm{m})$ was assumed to be constant for the cohort followed, it can be determined, as described by Anastácio and Marques [4], from:

$$
\mathrm{m}=|-\mathrm{b} \times \ln 10|
$$

where $b$ is the parameter of the density equation.

The fraction of a cohort present at the start of a year which actually dies during the year can be expressed numerically by the following expression:

$$
\mathrm{A}=\mathrm{D} / N_{0}
$$

where $\mathrm{A}$ is the annual mortality rate, $\mathrm{D}$ the number of deaths during the year and $N_{0}$ is the number of fish present at the start of a year [31]. The instantaneous mortality rate $(\mathrm{Z})$ was also calculated for mean age and mean life span estimations. $\mathrm{Z}$ is equal to the natural logarithm (with sign changed) of the complement of the annual mortality rate [31] and very close to the yearly multiple of $\mathrm{m}$ :

$$
\mathrm{Z}=-\ln (1-\mathrm{A}) \approx \mathrm{m} \times 365
$$

For exponential mortality at a constant rate, mean age and mean life span are equal and, except when growth is exponential, both are equal to the reciprocal of the instantaneous mortality rate [2]:

$$
\mathrm{L}=1 / \mathrm{Z}
$$

where $\mathrm{L}$ is mean age and mean life span.

Fecundity was estimated by using an index of adjusted fecundity, which was defined as the number of embryos carried by a female divided by her SL [21]. With regard to fertilization, the first unambiguous stage of development is stage 3 [29], so all analysis concerning fecundity were conducted on stage 3 or older embryos. The length of the reproductive season was determined by calculating the time interval between 1 month before the presence of the first immature (since a typical gestation period is about 4 weeks [30]) and the presence of the last newborn/ small immature.

Production was estimated using Allen curves [37]. A year-to-year (or cohort-to-cohort) stability was assumed and the method was used for the mixed-age population. In these cases, a single cohort production will be equal to the annual production of all the population [37]. The Allen curve method does not use directly the values corresponding to the population, but relies on the values of a curve adjusted to the original data. This process allows for the correction of some of the bias in data. The production estimate for the population was achieved by determining the aver- age AFDW and density of mosquitofish, both against time. Then, density was plotted against average AFDW for each sampling date, where production was given by the integral of the curve adjusted to this plot.

The average biomass was determined by the ratio of the biomass integral within a given time interval and the time interval [2]. Assuming the same cohort-tocohort stability presupposition used for production estimation, the total biomass in a given time was the product of individual average weight (AFDW) and the density of the mixed-age population.

Stepwise multiple-regression analysis models [39] were developed in which abundance, sex-ratio, percentage of gravid females and fecundity were correlated with water temperature, water volume, dissolved oxygen, $\mathrm{pH}$, conductivity and photoperiod. A stepdown procedure was followed in order to examine, in the first place, the effect of each environmental variable on the others, with the least significant variable being removed at every step. The analysis stopped when all the remaining variables had a significant correlation level $(P<0.05)$ [39]. Tests for normality, Kolmogorov-Smirnov, and for homogeneity of variances, Cochran's C and Bartlett's, were performed for the dependent variables before effecting the multipleregression analysis [39]. Following the tests results, neither of the variables needed to be transformed.

\section{RESULTS}

\subsection{Physicochemical factors}

The irrigation channel had the following environmental characteristics (average $\pm \mathrm{SE}$ ): water temperature: $18.4 \pm 1.5^{\circ} \mathrm{C}$, with a minimum of $9.4^{\circ} \mathrm{C}$ and a maximum of $25.2^{\circ} \mathrm{C}$; dissolved oxygen: $5.7 \pm 0.7 \mathrm{mg} \cdot \mathrm{L}^{-1}$, with a minimum of $2.8 \mathrm{mg} \cdot \mathrm{L}^{-1}$ and a maximum of $10.9 \mathrm{mg} \cdot \mathrm{L}^{-1}$; $\mathrm{pH}: 7.3 \pm 0.2$, with a minimum of 6.6 and a maximum of 8.8 ; conductivity: $318.3 \pm 36.3 \mu \mathrm{S}$, with a minimum of $133.6 \mu \mathrm{S}$ and a maximum of $553.0 \mu \mathrm{S}$; and water volume: $362677 \pm 60473 \mathrm{dm}^{3}$, with a minimum of $22666 \mathrm{dm}^{3}$ and a maximum of $586707 \mathrm{dm}^{3}$.

\subsection{Population structure and reproduction}

It was possible to recognize and track two annual cohorts for both sexes, the 1995 and 1996 cohorts (figures 2, 3). For the immature-females histograms, the beginning of the 1997 cohort was also recognized in the last sampling date (figure 2). Females occurred as a single mode group from April-May (1996), at which time first reproduction occurred, about a month before the presence of the first newborns $(<15 \mathrm{~mm})$. Bimodal distributions were plainly observed thereafter 

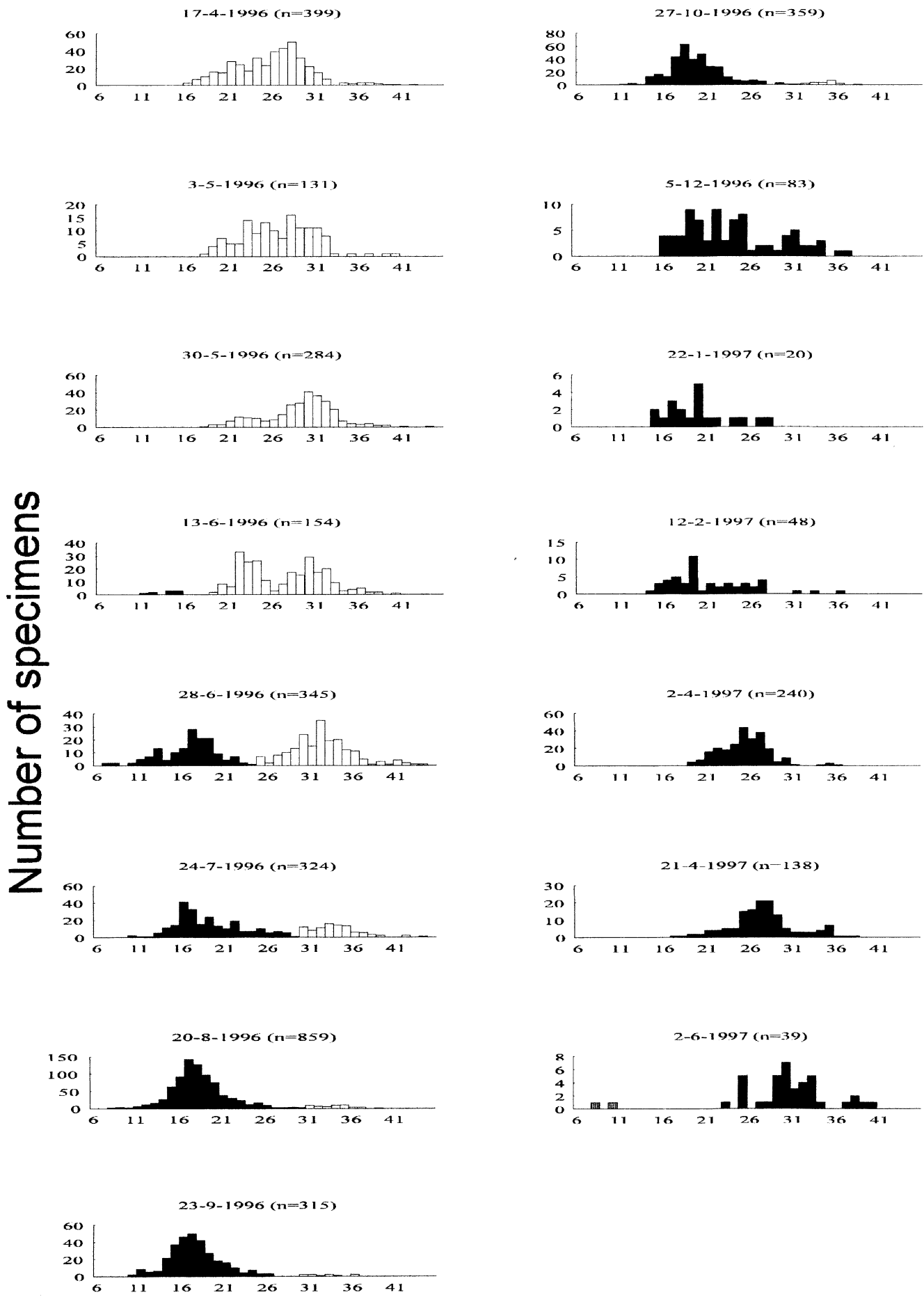

\section{Standard length ( $\mathrm{mm}$ )}

Figure 2. Length-frequency distribution of the 1995 (white polygons), 1996 (black polygons), and 1997 (grey polygons) immature-female cohorts of Gambusia holbrooki caught throughout the study period.

Vol. 20 (6) 1999 

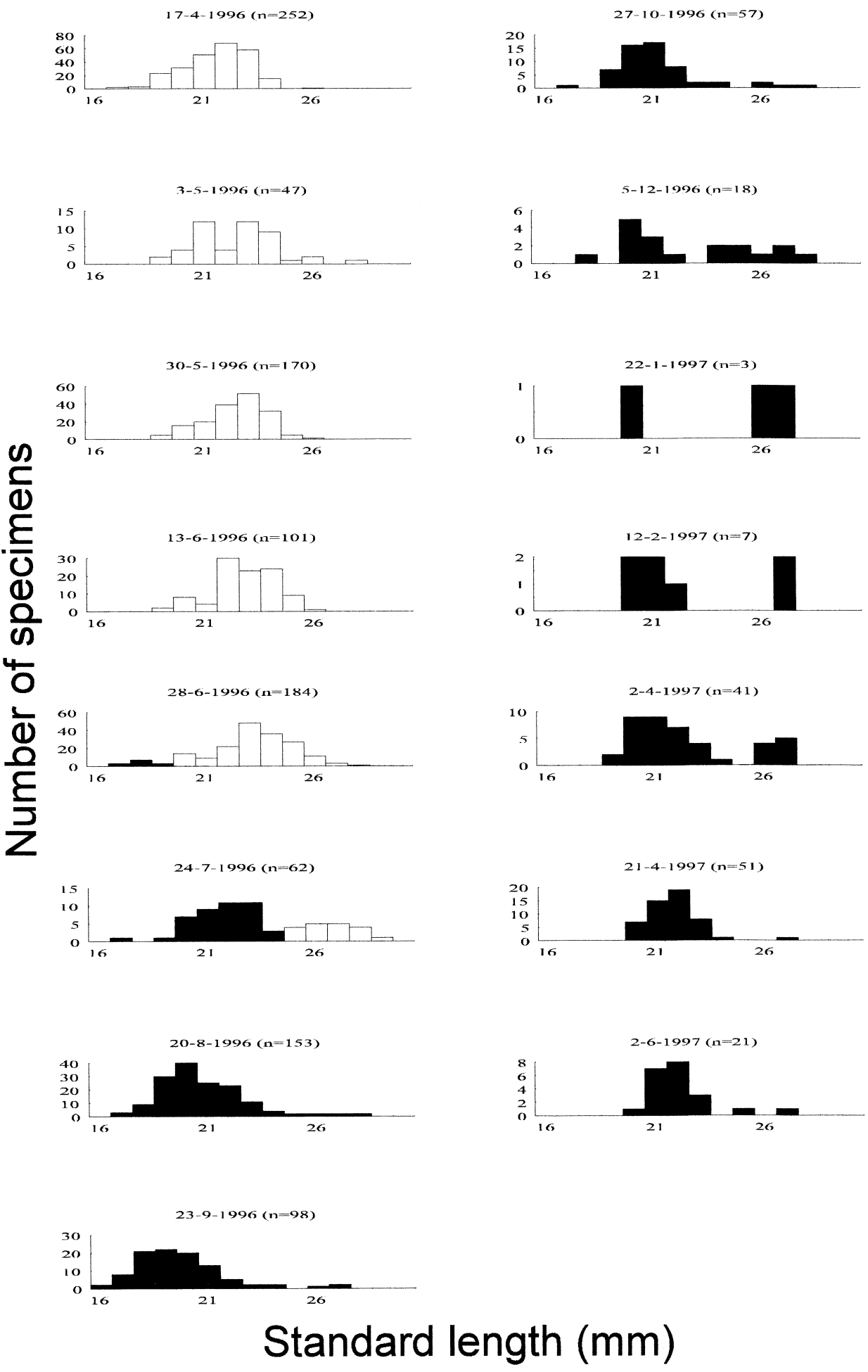

Figure 3. Length-frequency distribution of the 1995 (white polygons), and 1996 (black polygons) male cohorts of Gambusia holbrooki caught throughout the study period. 


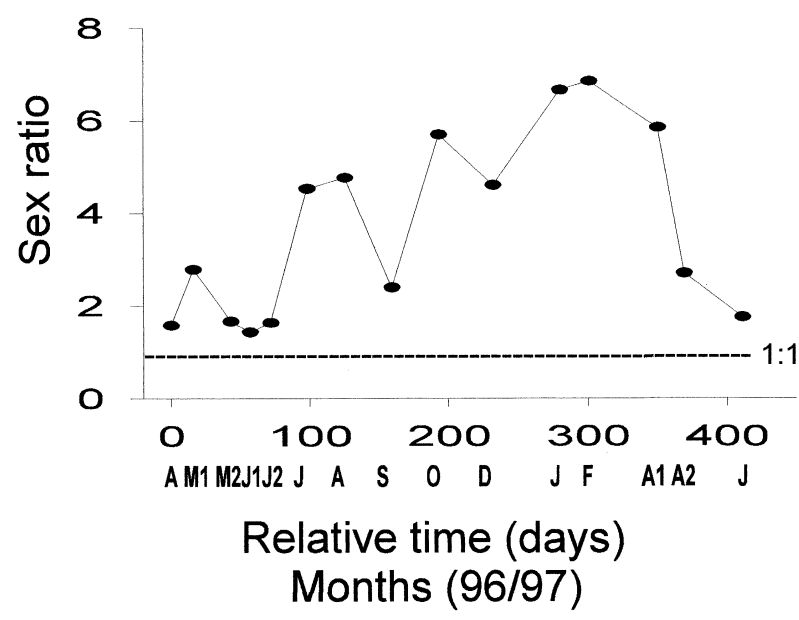

Figure 4. Sex ratios (females per male) of Gambusia holbrooki caught from April 1996 to June 1997. The initials of the months with numbers (1 and 2) correspond to samples made fortnightly. For example, the sequences $\mathrm{J} 1, \mathrm{~J} 2$ and $\mathrm{J}$ represent the two fortnightly samples of June and the monthly sample of July (1996), respectively.

until August. Nevertheless, it is possible that the two cohorts may be partially mixing together in the inflexion-point zone, especially from August to October. Recruitment occurred from June through October, at which time the last newborns were collected. From December onwards, an unimodal distribution of females was observed until the beginning of the next recruitment in June 1997 (figure 2). Males were represented as a single modal group in all collections except those following the first periods of immature recruitment that coincides with the male cohort transition (figure 3). This last process becomes complete about 3 months after the first recruits. Since males have essentially little growth after maturation, some degree of blending of the two cohorts around the inflexion-point is also possible from June to August.

Females outnumbered the males during the entire study period, with an average sex-ratio of $4: 1$. Nevertheless, there was a temporal variation in the proportion. Sex-ratios approached unity from April to June (1996) except for the first sample in May, but females made up a large proportion of the population shortly after the beginning of recruitment (July), during the remaining reproductive season (until October) and winter/early spring period (figure 4). After this long period (approximately $270 \mathrm{~d}$ ), sex-ratios again approached unity, just before the next recruitment in June 1997 (figure 4).

Inspection of the developmental stage of the female intra-ovarian cycle revealed that the most important period for reproduction falls within the time interval between April and August. The proportion of non-

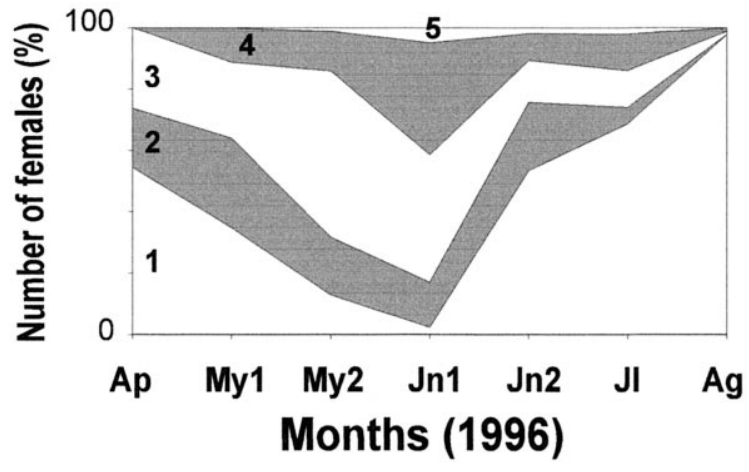

Figure 5. Changes in the percentage of female Gambusia holbrooki bearing eggs/embryos in each developmental stage $(1,2,3,4$ and 5, as defined in Materials and Methods) during the most important reproductive period (1 402 females were examined). The initials of the months with numbers (1 and 2) correspond to samples made fortnightly.

gravid females (stage 1) decreased until early June, whereas gravid females (especially stages 3-5) increased (figure 5). After the beginning of recruitment, the inverse trend occurs, and in August, only a very small proportion of females were gravid.

We considered three parameters to assess mosquitofish fecundity throughout the year (only for stage 3 and older stages): the average number of eggs/ embryos per female, egg diameter and adjusted fecundity index. The average brood size (embryos) reached its maximum in July 1996 (32 embryos per female) for the 1995 cohort, at which time there were almost no unfertilized eggs in the ovaries (figure 6a), and in early June 1997 (34 embryos per female) for 1996 cohort (our last data). For both cohorts, a first small peak that seemed to be recognizable in April may result from the contribution of old males for the first pulse of female fertilization, whereas the increasing relative abundance of the new male cohort in June-July (figure 3) during the cohort-to-cohort transition was probably responsible for the following pulse. The pattern of the average adjusted fecundity index confirms these trends, reaching its maximum values in July 1996 (0.95) and in June 1997 (1.05) (figure 6c); nevertheless, the individual maximum brood size (91 embryos from a total of 117 eggs) was recorded in late June 1996. The average egg diameter increased more or less continuously throughout the most important reproductive period, reaching its maximum value $(2519 \mu \mathrm{m})$ in August (figure 6b). After August, reproduction ceased until the next reproductive season (figure 6).

\subsection{Growth}

The average monthly lengths and their respective standard deviations depict a seasonal variation in 


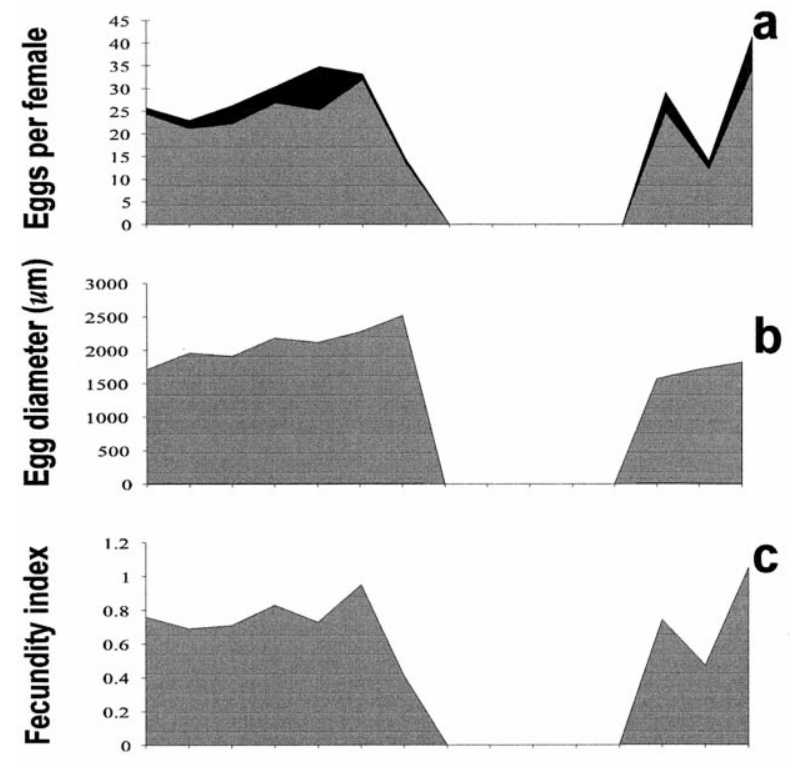

Ap My1My2 Jn1Jn2 JI Ag St Oc Dc Ja Fb Ap1Ap2 Jn

\section{Months (96/97)}

Figure 6. Seasonal changes of the fecundity parameters considered for Gambusia holbrooki throughout the period studied: a) average total number of eggs (in black the fraction of non-fertilized eggs) and embryos (in grey) per female; b) average egg diameter; and c) average adjusted fecundity index. In total, 287 females were investigated. The initials of the months with numbers (1 and 2) correspond to samples made fortnightly.

growth for immature and females combined, and males (figure 7). Therefore, we took seasonal variations into consideration, and growth data were used to calibrate a growth model proposed by Gaschütz et al. [20]. Two main cohorts were tracked for both sexes during a total period of $411 \mathrm{~d}$. Since the study period was not sufficient to contain the entire life cycle of a single cohort, we adjusted a growth curve for each sex to the original data of the 1996 cohort merged with the last data on the 1995 cohort. The fit was compared based on $r^{2}$ values. The growth-data-fitted Gaschütz's model well predicted the results for immature and female combined ( $r^{2}=0.96$ for seventeen data points), but not for males $\left(r^{2}=0.67\right.$ for thirteen data points). The growth pattern of males is different since some of them essentially stop growing after maturation (figure 7). Therefore, we used this method only for immature and females (figure 8), the fraction of the population with a continuous growth. The model parameters for this group were estimated as follows: $\mathrm{L}_{\infty}=48.5 \mathrm{~mm}$ (SL), converted from the maximum TL value described by Vondracek et al. [36], larger than

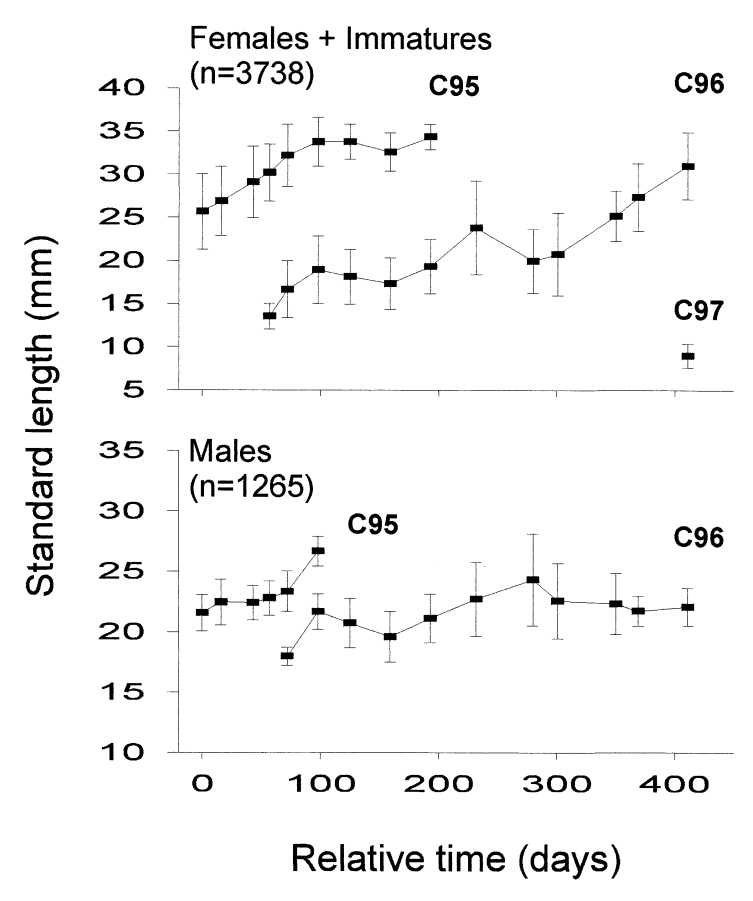

Figure 7. Annual growth pattern in females and immature combined, and males from the 1995 (C95), 1996 (C96) and 1997 (C97) cohorts of Gambusia holbrooki, based on monthly averages of standard length $(\mathrm{mm})$. The standard deviations from the mean are also indicated.

the maximum value we observed (some females with $44 \mathrm{~mm} \quad \mathrm{SL}) ; \quad t_{0}=-0.395 ; \quad t_{\mathrm{s}}=-0.123 ; \mathrm{k}=0.675$; $\mathrm{C}=1.061$; and $\mathrm{D}=1$, since Gambusia holbrooki, as a cyprinodont, has an $\mathrm{O}_{2}$-consumption proportional to Von Bertalanffy's '2/3 rule of metabolism' [20].

There was an initial stage with notable growth $\left(0.076 \mathrm{~mm} \cdot \mathrm{d}^{-1}\right)$, corresponding to the months with mild temperatures (early first summer) and initial recruitment of a new cohort (figure 8). This period was followed by a second stage of extremely slow growth $\left(0.014 \mathrm{~mm} \cdot \mathrm{d}^{-1}\right)$ between the end of summer and the 'cold months' from autumn to mid-winter, and a final phase, with a recovery in growth $\left(0.052 \mathrm{~mm} \cdot \mathrm{d}^{-1}\right)$ until the end of the second summer (figure 8). For males, we assumed a growth rate similar to the first stage until maturity (approximately with $20 \mathrm{~mm} \mathrm{SL}$ ) and, thereafter, a second stage growth rate for the remaining male life cycle.

\subsection{Density, mortality, mean age and mean life span}

For all mixed-age population, the mosquitofish showed the same density patterns throughout the study period for the three main 'sexual' categories consid- 


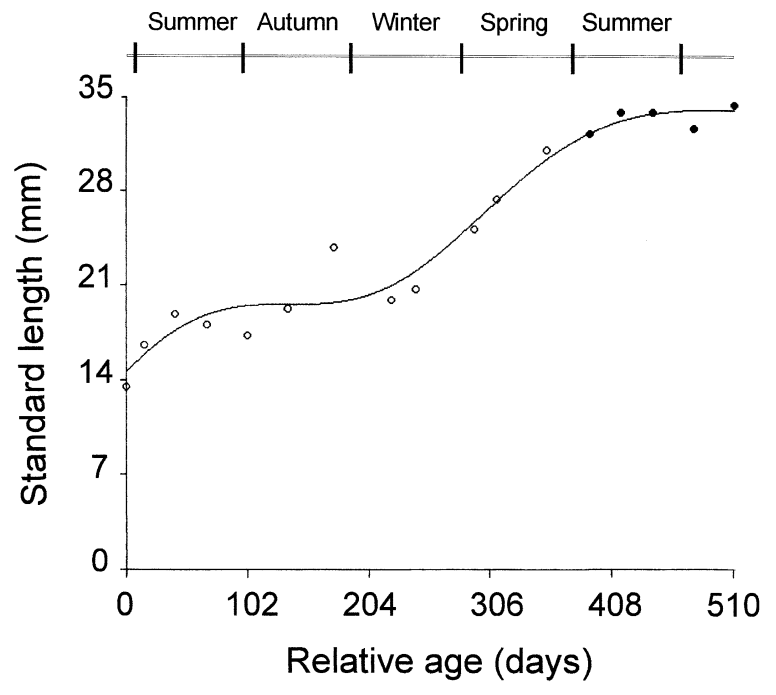

Figure 8. Gaschütz's growth model of standard length $(\mathrm{mm})$ for the 1996 female + immature cohort, merged with the last data on the 1995 cohort, of Gambusia holbrooki. Data points used to calibrate the model are also plotted (the last five black data points belong to the 1995 cohort).

ered: females (non-gravid and gravid), males and immature. Females and males maintained, with small oscillations, relatively low density values until the mid-recruitment period (approximately until day 100) (figure 9). Thereafter, the densities of both sexes increased abruptly, reaching their respective maximum during mid-summer (day 100 to 130), decreased gradually until the early winter (before day 230), maintaining posteriorly again the relatively low values until just before the next recruitment (before day 400) (figure 9). The density of immature followed the same trend, but obviously was limited to the reproductive season (day 50 to 200) (figure 9).

The density of the 1996 cohort on each sampling date allowed an estimate of the daily mortality rate for both sexes. This cohort was merged with the last data on the 1995 cohort, for the same reason as explained for the growth analysis. Since the sex-ratio at birth in mosquitofish is 1:1 [26], we assumed that each sex contributed $50 \%$ of the immature density. The daily mortality rate was estimated by the adjustment of a negative exponential curve $\left(y=\mathrm{a} \times 10^{-\mathrm{b} x}\right)$ to the densities of each sex detected from the recruitment period, when they reached its maximum density value, to the period where all the respective individuals disappeared (figure 10). Sampling constraints related to environmental conditions, such as the drastic increase of the water interchange between rice paddies and irrigation channels during winter, might have caused bias in the data available for these calculations. Actually, the

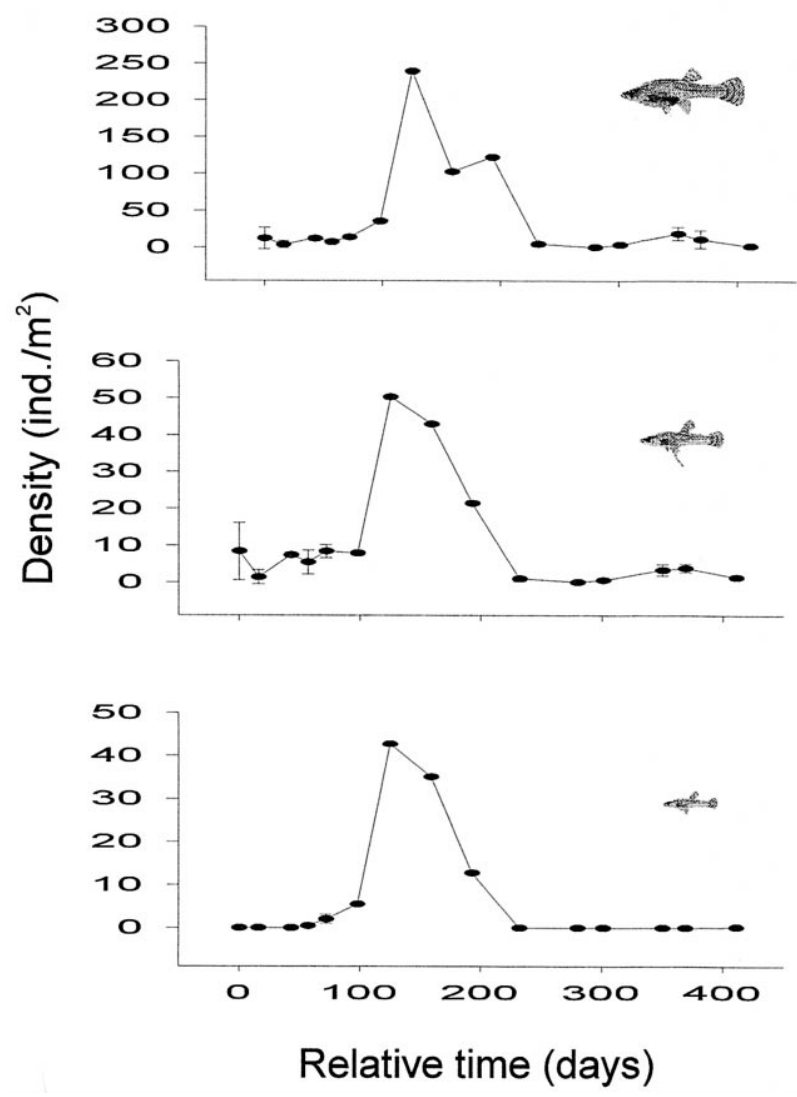

Figure 9. Variation of the average density of Gambusia holbrooki throughout the study period. The mixed-age females and males (top and middle graphics) and immature (bottom graphic) are considered separately. The standard deviations from the mean are also indicated.

increase of the total area due to the inundation of rice fields, which work as total open-systems during the winter period, may have caused an 'underestimation' of the densities on irrigation channels when compared with the densities estimated in a more or less stable closed-system, prevailing during the remaining period. This problem was partially solved by not taking into consideration winter data points, since their extreme low values seemed not to make biological sense. The mortalities, mean age and mean life span parameters estimated for both sexes from the density equations are given in table I. Females were longer-lived, with smaller mortality rates than males.

\subsection{Influence of environmental factors}

A stepwise multiple-regression analysis was used to search for significant correlations between some biological and demographic parameters of mosquitofish and the following environmental variables: dissolved 


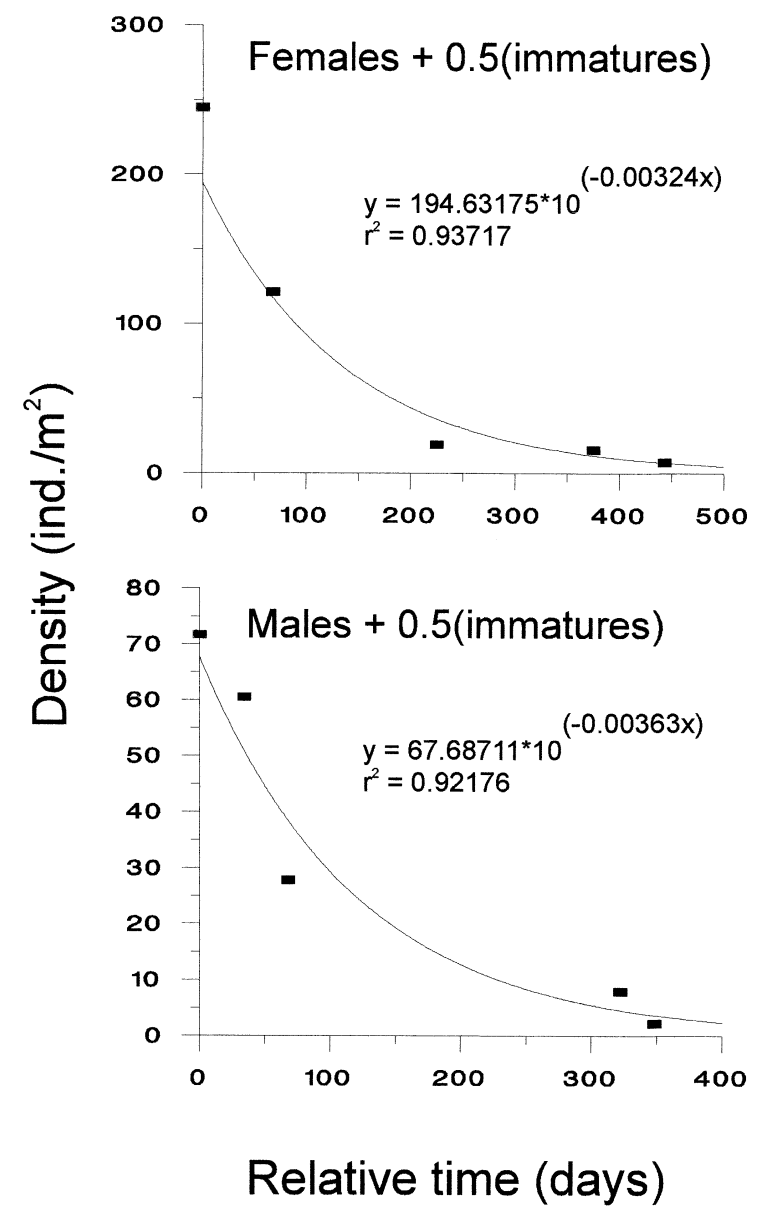

Figure 10. The survivorship curve for both sexes of a Gambusia holbrooki cohort (1996 cohort merged with the last data on 1995 cohort). A negative exponential curve $\left(y=\mathrm{a} \times 10^{-\mathrm{b} x}\right)$ was adjusted to the densities throughout time. $x$ and $y$ are time in days and density (individuals $\cdot \mathrm{m}^{-2}$ ), respectively. A total of $50 \%$ of the immature density was considered as belonging to each sex. The respective functions and $r^{2}$ values are also indicated. oxygen, water temperature, $\mathrm{pH}$, conductivity, water volume and photoperiod. Photoperiod seemed have the greatest effect on biotic parameters. The percentage of gravid females and fecundity index were positively correlated with photoperiod (PHO), and sex-ratio was negatively correlated with this factor (table II). On the other hand, photoperiod was positively correlated with water temperature $(r=0.85, P<0.001)$ and water volume $(r=0.66, P<0.01)$. The correlations between biotic parameters and these environmental factors cannot be defined as cause-and-effect, since most were also intercorrelated. Moreover, water temperature (TMP) and volume (VOL) did not influence all mosquitofish parameters (table II). The total density of mosquitofish was positively correlated with conductivity (CND), and the fecundity index was positively correlated with $\mathrm{pH}$ and negatively correlated with dissolved oxygen (OXI) and conductivity (CND) (table II).

\subsection{Production estimates, average biomass and $\mathrm{P} / \mathrm{B}$ ratio}

Production was estimated from a plot of the relationship between the density and the average weight of the mixed-age population (Allen curve method). A curve of the type $y=\mathrm{a} \times 10^{-\mathrm{b} x}$ was then adjusted to data points. The resulting figure is basically a growthsurvivorship curve with the density of survivors plotted against mean individual ash-free dry weight (AFDW) (figure 11a), and the total production within the study period $(411 \mathrm{~d})$ being given by the integral of this function (table III). Production (P) was then estimated as $3.10 \mathrm{~g} \cdot \mathrm{m}^{-2} \cdot$ year $^{-1}$ (AFDW).

Total biomass values for each sampling date were estimated from the products of densities and average weights (AFDW) of the mixed-age population. A fourth order polynomial function was then adjusted to these data (figure 11b), and the average biomass (B) was calculated by dividing the integral of this function within the study interval by 411 (table III). The obtained value was $2.90 \mathrm{~g} \cdot \mathrm{m}^{-2}$ (AFDW). The $\mathrm{P} / \mathrm{B}$ ratio was then estimated as 1.07 .

Table I. Estimated parameters for mortalities, mean age and mean life span of both sexes from the functions describing the evolution of a Gambusia holbrooki cohort density. Only $50 \%$ of the immature density was considered as belonging to each sex. b is the parameter of the density equations of the type $y=\mathrm{a} \times 10^{-\mathrm{b} x}$. $\mathrm{D}$ is the number of deaths during the year and $N_{0}$ is the number of fish present at the start of a year.

\begin{tabular}{lccc}
\hline Parameters & Equations & Females + 0.5 (immatures) & Males + 0.5 (immatures) \\
\hline Daily mortality rate $(\mathrm{m})$ & $\mathrm{m}=|-\mathrm{b} \times \ln 10|$ & 0.00746 & 0.00836 \\
Annual mortality rate $(\mathrm{A})$ & $\mathrm{A}=\mathrm{D} / N_{0}$ & 0.93432 & 0.95268 \\
Instantaneous mortality rate $(\mathrm{Z})$ & $\mathrm{Z}=-\ln (1-\mathrm{A})$ & 2.72304 & 3.05081 \\
Mean age and mean life span $(\mathrm{L})$ & $\mathrm{L}=(1 / \mathrm{Z}) \times 365$ & $134.04 \mathrm{~d}$ & $119.64 \mathrm{~d}$ \\
\hline
\end{tabular}


Table II. The $t$-values, the regression equations, the coefficient of determination $\left(r^{2}\right)$, the F-values and significance levels $(* P<0.05 ; * *$ $P<0.01$; *** $P<0.001)$ of the correlates, selected by automatic stepwise regression analysis as factors with significant influence on the variation in the biological parameters selected for mosquitofish (Gambusia holbrooki), are shown. The codes of the independent variables are: dissolved oxygen (OXI), water temperature (TMP), pH, conductivity (CND), water volume (VOL), and photoperiod (PHO). For variables not selected, the $t$-values are not shown (ns, non-significant).

\begin{tabular}{|c|c|c|c|c|c|c|c|}
\hline \multirow[t]{2}{*}{ Parameters } & \multicolumn{6}{|c|}{ Independent variables ( $t$-values) } & \multirow[t]{2}{*}{ Equations } \\
\hline & OXI & TMP & $\mathrm{pH}$ & CND & VOL & $\mathrm{PHO}$ & \\
\hline Total density & ns & ns & ns & $3.799 * *$ & ns & ns & $\begin{array}{l}=-97.122+0.485(\mathrm{CND}) \\
\qquad\left(r^{2}=0.53, \mathrm{~F}=14.43^{*} *\right)\end{array}$ \\
\hline Gravid females (\%) & $\mathrm{ns}$ & ns & $\mathrm{ns}$ & ns & $\mathrm{ns}$ & $4.325 * * *$ & $\begin{array}{l}=-1.179+0.110(\mathrm{PHO}) \\
\quad\left(r^{2}=0.59, \mathrm{~F}=18.71^{* * *}\right)\end{array}$ \\
\hline Sex-ratio & $\mathrm{ns}$ & $\mathrm{ns}$ & ns & $\mathrm{ns}$ & $\mathrm{ns}$ & $-3.204 * *$ & $\begin{array}{l}=11.698-0.601(\mathrm{PHO}) \\
\qquad\left(r^{2}=0.44, \mathrm{~F}=10.27 * *\right)\end{array}$ \\
\hline Fecundity index & $-3.749 * *$ & ns & $2.719^{*}$ & $-3.444 * *$ & $\mathrm{~ns}$ & $8.006^{* * * *}$ & $\begin{array}{c}=-2.487-0.072(\mathrm{OXI})+0.232(\mathrm{pH}) \\
-0.001(\mathrm{CND})+0.153(\mathrm{PHO}) \\
\left(r^{2}=0.93, \mathrm{~F}=34.27 * * *\right)\end{array}$ \\
\hline
\end{tabular}

\section{DISCUSSION}

Like other populations of Gambusia holbrooki previously studied in the Iberian peninsula $[15,35]$, the population in the rice fields of the lower Mondego River Valley consisted of two main annual cohorts with a cohort substitution during the reproductive season. Males from the parental cohort did not survive the mid-reproductive season, with no representation in August, and parental females disappeared after the reproduction period.

In the lower Mondego River Valley, the reproductive season (April-October) was similar to those of populations in other areas of the Iberian peninsula [15, 19, 35]. The maximum average adjusted fecundity (embryos $\cdot \mathrm{mm}^{-1}$ ) of mosquitofish occurred in July 1996 and June 1997 (our last data), the middle of the reproductive period, when females reached their longer average size. Actually, mosquitofish fecundity is a function of female size and reproductive sta- tus [21], although the brood size is not constant in the largest and oldest females [26]. The apparent bimodality of the adjusted fecundity, especially for the 1996 cohort, may suggest that the population had a bivoltine cycle. Fernández-Delgado and Rossomano [15] reported that mosquitofish in the Zoñar lagoon clearly showed two distinct reproductive periods: a first period where all adults reproduced (spring - when this period ended, there was a halt in reproduction during which the parental generation disappeared); and a second period when offspring of the first cohort reached the size to reproduce (late summer). Botsford et al. [6] observed a similar pattern in the development of western mosquitofish (G. affinis) stocks for mosquito control in rice fields of California. In the current study, we considered these two possible events in the same reproductive period, because there was no halt in reproduction and only a single peak of immature density was observed. Moreover, the parental genera-

Table III. Estimation of the total productivity and the average biomass for the mixed-age Gambusia holbrooki population during the study period. The functions adjusted to data and the respective $r^{2}$ are shown. The total production and biomass integral are the integration of the functions on a given interval. $x$ and $y$ are respectively ash-free dry weight $(\mathrm{g})$ and density (individuals $\left.\cdot \mathrm{m}^{-2}\right)$, for production estimation; and $w$ and $z$ corresponds respectively to the biomass values $\left(\mathrm{g} \cdot \mathrm{m}^{-2}\right)$ and to the time (d) passed from the beginning of sampling, for average biomass estimation.

\begin{tabular}{|c|c|c|c|c|c|}
\hline \multirow[b]{2}{*}{ Parameters } & \multirow[b]{2}{*}{ Expressions } & \multirow[b]{2}{*}{$r^{2}$} & \multicolumn{2}{|c|}{ Integration limits } & \multirow[b]{2}{*}{ Value } \\
\hline & & & Minimum & Maximum & \\
\hline Total production & $y=865.675 \times 10^{(-26.871 x)}$ & 0.81987 & $0.022 \mathrm{~g}$ & $0.081 \mathrm{~g}$ & $3.49\left(\mathrm{~g} \cdot \mathrm{m}^{-2}\right)$ \\
\hline Biomass integral (i) & $w=0.785-6.4 \times 10^{-3} z+3.9 \times 10^{-4} z^{2}-1.8 \times 10^{-6} z^{3}+2.2 \times 10^{-9} z^{4}$ & 0.94519 & $0 \mathrm{~d}$ & $411 \mathrm{~d}$ & $1190.45\left(\mathrm{~g} \cdot \mathrm{m}^{-2}\right)$ \\
\hline Average biomass (B) & $=\mathrm{i} / 411$ & & & & $2.90\left(\mathrm{~g} \cdot \mathrm{m}^{-2}\right)$ \\
\hline
\end{tabular}



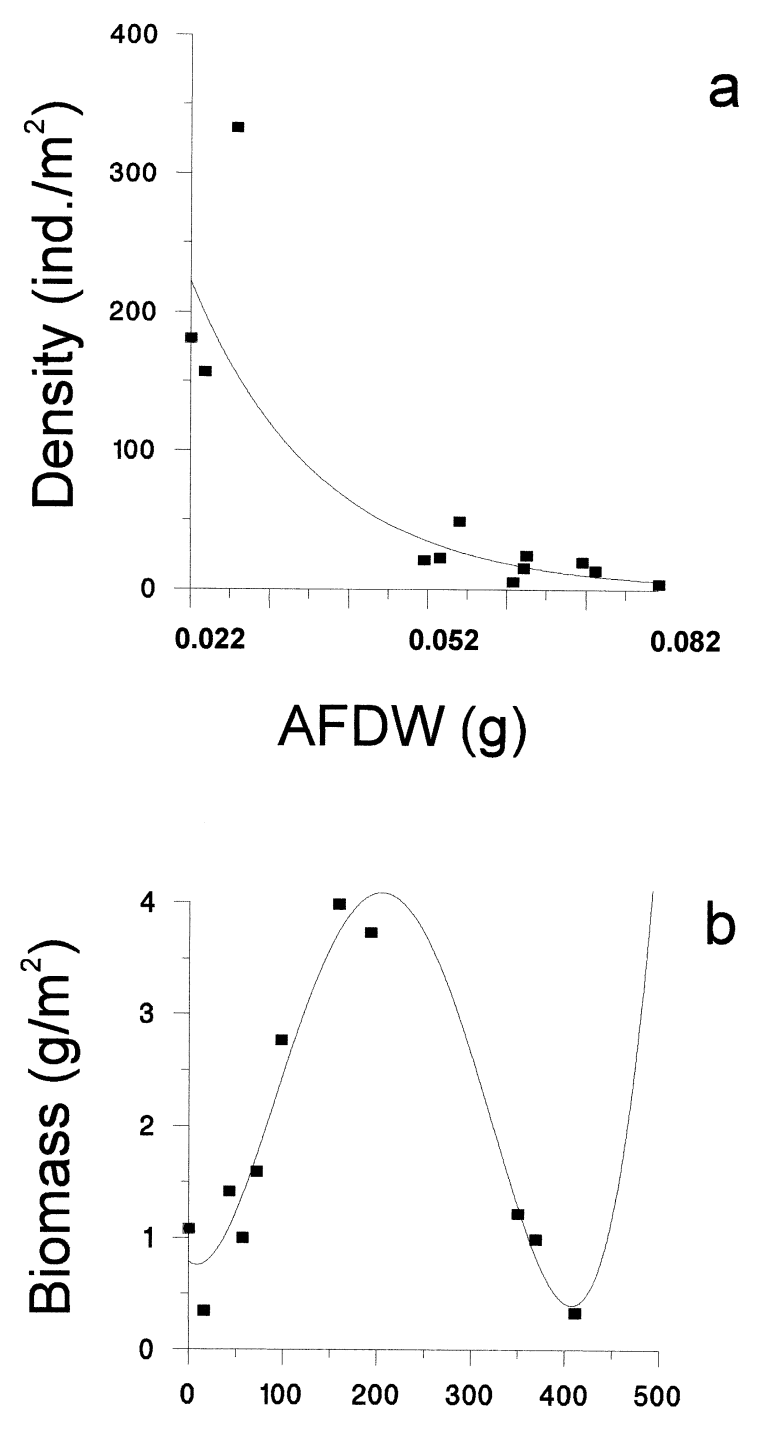

Relative time (days)

Figure 11. Models used to estimate Gambusia holbrooki total production and average biomass, respectively: a) adjustment of the Allen curve to the relationship between the density and the average ash-free dry weight (AFDW) of mixed-age population; and b) adjustment of a polynomial curve to the estimated values for total biomass throughout the study period. Data points used to calibrate the models are also plotted. The respective functions are shown in table III.

tion did not disappear after the beginning of the most important reproductive period (from April to August), at which time a crossed-fertilization between the cohorts must be considered, especially between the young mature males and oldest females. In fact, only a very small fraction of the young females seemed to be reproductively active at the end of August. Therefore, this was no synchronous bivoltine reproduction. Vargas and Sostoa [35] also reported a non-synchronized reproduction for the mosquitofish population in the Ebro delta. Like other species of the genus Gambusia, the ability of mosquitofish to adapt to different often harsh habitats by modifying its life history [21] could explain the life history differences between populations from the rice field irrigation channels in the lower Mondego region and other regions.

Photoperiod seemed to be the major factor with influence on seasonal fecundity of the population studied, since the percentage of gravid females and the adjusted fecundity index increased when photoperiods were longer. In fact, the reproductive cycles of mosquitofish populations are influenced by the seasonal fluctuations of photoperiod rather than temperature [21]. Cech et al. [10] experimentally reported that long photoperiods accelerated the chronology of reproduction in mosquitofish. Moreover, Fraile et al. [17] also observed experimentally that mild temperatures are necessary and sufficient for male mosquitofish spermatocyte formation, but not sufficient for meiosis and spermiogenesis, because these processes also require long photoperiods.

As in other areas of the Iberian peninsula, a disproportionately large number of females were found. In our study, the average sex-ratio of 4:1 (females per male) was similar to the value described for the Canal Vell lagoon (4:1) by Vargas and Sostoa [35] in NE Spain, and smaller than the value described for Águas de Moura rice fields (5:1) by Franca and Franca [19] in Portugal. The opposite situation was reported by Fernández-Delgado and Rossomano [15] in the Zoñar lagoon (SW Spain), where males dominated in numbers. Nevertheless, the wild populations of many poeciliids normally have greater number of females, biased adult sex-ratios in both directions are wellknown in the Poeciliidae family, composed mostly by species with an accentuated sexual dimorphism [7, 19, $21,26]$. Since equal numbers of male and female mosquitofish occur in the ovary and at birth [26], the temporal variation in the adult sex-ratio must be attributed to the differential mortality of the sexes. In this study, sex-ratios approached unity from April to June (figure 4). In April, females become gravid and their percentage increased progressively until early June, when most females were gravid (figure 5). The reason for these trends may be related to selective predation on gravid females. Britton and Moser [7] 
reported that gravid females may be more visible (volume increase and dark spots on the abdomen) and more susceptible (slow movements) to predators than non-gravid females and males. At this period, since mosquitofish predators, such as herons (e.g. Egretta garzetta and Ardea cinerea), white stork (Ciconia ciconia), kingfisher (Alcedo atthis) and aquatic snakes, are very abundant in the lower Mondego rice fields, predation on females may skew the sex-ratio in favour of males. During the following months, the percentage of gravid females decreased and once more females made up the larger proportion of the population during the remaining reproductive season (until October) and winter/early-spring period. Increased male mortality after recruitment may be due to the fact that, in comparison with females, smaller sizes may lead to higher susceptibility to environmental stressors that prevail from August on [8], such as the diminution of resources and starvation (Frias, in prep.), overcrowding [26] and hypoxia [9]. The higher daily and annual mortality rates of males from the population studied may reflect this greater susceptibility.

Maximum growth occurred during the early summer, when the temperatures become mild and the availability of food, especially zooplankton, increases (Cabral, unpubl. data). These conditions are favourable for increasing mosquitofish metabolic rate [9] and food consumption [27], promoting high growth rates. Females had a pattern of indeterminate growth with seasonal variation [13]: growth slows during the "cold months' until the mid-winter and then recover with relatively high rates until the end of the second summer. The growth of adult males did not follow this pattern, because it is associated with the onset of maturation, growth cessation or slow growth, after the gonopodium has been completely formed [26, 36]. The estimated growth rates, taking into consideration seasonal variations by using the model proposed by Gaschütz et al. [20], were about one order of magnitude smaller than the values described for the Canal Vell [35] and Zoñar lagoons [15]. The possible cause of this may be related with the fact that the adjustment of the seasonal growth curves to the original data for long periods (several months) may skew the growth rates to lower values than when they are directly estimated for short favourable periods (1-2 months), as performed in the studies mentioned above. Moreover, this type of adjustments to the monthly averages of length at successive cohorts allows correction of some of the bias in data [31].

With regard to mosquitofish annual production and $\mathrm{P} / \mathrm{B}$ ratio, no estimates are available for other mosqui- tofish populations from the literature, so we have no idea of the general levels to be expected. Nevertheless, the estimated mosquitofish annual production of $3.10 \mathrm{~g} \cdot \mathrm{m}^{-2} \cdot$ year $^{-1}$ (AFDW), approximately $12.63 \mathrm{~g} \cdot \mathrm{m}^{-2}$ $\cdot$ year $^{-1}$ (wet weight) and $126.26 \mathrm{~kg} \cdot \mathrm{ha}^{-1} \cdot$ year $^{-1}$ (wet weight), seem to be an extraordinary value for a very small fish species, much higher than, for instance, the values estimated for other planktivore populations studied in lakes from the ex-USSR and reviewed by Waters [37], which range from 9-24 kg.ha ${ }^{-1} \cdot$ year $^{-1}$. The $\mathrm{P} / \mathrm{B}$ ratio of 1.07 , is also elevated when compared with values of these planktivore populations, which range from $0.7-0.8$, indicating in this case that mosquitofish have a faster growth and a shorter life span [37].

\section{CONCLUSION}

A combination of life history, population dynamics, production and eco-ethological traits (e.g. fast growth, reduced longevity, viviparity, high productivity, an intermediate position in food chain, plasticity and adaptability in its food use [8], and no special habitat requirements for reproduction) show that G. holbrooki, introduced into rice fields all over the world, certainly induce an important impact in the structure and functioning of the native biological communities of these important agro-ecosystems, such as in those of the lower Mondego River Valley. This question is extremely important to reinforce the recommendation that Gambusia, the backbone of biocontrol for onequarter of a century [32], not be introduced into new areas.

\section{Acknowledgments}

The present study was supported by the EU throughout the R and D project AIR 3-CT 94-2432 and by FCT (Portuguese National Board of Scientific Research). The authors are indebted to Cláudia Mieiro, Ruth Carvalho and Sofia Ávila who assisted in the field and laboratory work.

\section{REFERENCES}

[1] Albuquerque R.M., Peixes de Portugal e Ilhas adjacentes. Chaves para a sua determinação, Port. Acta Biol. 5B (1956) $1164 \mathrm{p}$.

[2] Allen K.R., Relation between production and biomass, J. Fish. Res. Board Can. 28 (1971) 1573-1581.

[3] Almaça C., Freshwater fish and their conservation in Portugal, Biol. Conserv. 72 (1995) 125-127.

[4] Anastácio P.M., Marques J.C., Population biology and production of the Red Swamp Crayfish Procambarus clarkii 
(Girard) in the Lower Mondego River Valley, Portugal, J. Crustacean Biol. 15 (1995) 156-168.

[5] Blaustein L., Larvivorous fishes fail to control mosquitoes in experimental rice plots, Hydrobiologia 232 (1992) 219-232.

[6] Botsford L.W., Vondracek B., Wainwright T.C., Linden A.L., Kope R.G., Reed D.E., Cech J.J., Population development of the mosquitofish, Gambusia affinis, in rice fields, Environ. Biol. Fish. 20 (1987) 143-154.

[7] Britton R.H., Moser M.E., Size specific predation by herons and its effect on the sex-ratio of natural populations of the mosquitofish Gambusia affinis Baird and Girard, Oecologia 53 (1982) 146-151.

[8] Cabral J.A., Mieiro C.L., Marques J.C., Environmental and biological factors influence the relationship between a predator fish, Gambusia holbrooki, and its main prey in rice fields of the Lower Mondego River Valley (Portugal), Hydrobiologia 382 (1998) 41-51.

[9] Cech J.J., Massingill M.J., Vondracek B., Linden A.L., Respiratory metabolism of mosquitofish, Gambusia affinis: effects of temperature, dissolved oxygen, and sex difference, Environ. Biol. Fish. 13 (1985) 297-307.

[10] Cech J.J., Schwab R.G., Coles W.C., Bridges B.B., Mosquitofish reproduction: effects of photoperiod and nutrition, Aquaculture 101 (1992) 361-369.

[11] Colwell A.E., Schaefer C.H., Effects of an insect growth regulator on plankton and Gambusia affinis, Aquat. Toxicol. 4 (1983) 247-269.

[12] Crivelli A.J., Boy V., The diet of the mosquitofish Gambusia affinis (Baird and Girard) (Poeciliidae) in Mediterranean France, Rev. Ecol. (Terre Vie) 42 (1987) 421-435.

[13] Daniels G.L., Felley J.D., Life history and foods of Gambusia affinis in two waterways of Southwestern Louisiana, Southwest. Nat. 37 (1992) 157-165.

[14] Fernández-Delgado C., Life-history patterns of the mosquitofish, Gambusia affinis, in the estuary of the Guadalquivir river of south-west Spain, Freshwater Biol. 22 (1989) 395-404.

[15] Fernández-Delgado C., Rossomano S., Reproductive biology of the mosquitofish in a permanent natural lagoon in southwest Spain: two tactics for one species, J. Fish Biol. 51 (1997) 80-92.

[16] Forés E., Comín F.A., Ricefields, a limnological perspective, Limnetica 8 (1992) 101-109.

[17] Fraile B., Sáez F.J., Vicentini C.A., González A., Miguel M.P., Paniagua R., Effects of temperature and photoperiod on the Gambusia affinis holbrooki testis during the spermatogenesis period, Copeia 1994 (1994) 216-221.

[18] Franca P., Determinação da idade em Gambusia holbrookii (Grd.), Bol. Soc. Port. Ciênc. Nat. 4 (1953) 198-204.

[19] Franca M.L.P., Franca P., Contribuição para o conhecimento de « Gambusia holbrookii » (Girard) aclimatada em Portugal, Arq. Mus. Bocage 25 (1954) 39-87.

[20] Gaschütz G., Pauly D., David N., A versatile Basic program for fitting weight and seasonally oscillating length growth data, Pelagic, Demersal and Shellfish Cttes, 1980, pp. 1-23.

[21] Haynes J.L., Cashner R.C., Life history and population dynamics of the western mosquitofish: a comparison of natural and introduced populations, J. Fish Biol. 46 (1995) $1026-1041$.
[22] Homski D., Goren M., Gasith A., Comparative evaluation of the larvivorous fish Gambusia affinis and Aphanius dispar as mosquito control agents, Hydrobiologia 284 (1994) 137-146.

[23] Hoy J.B., Experimental mass-rearing of the mosquitofish, Gambusia affinis, J. Am. Mosq. Control Assoc. 1 (1985) 295-298.

[24] Hubs C., Snails as a food source for Gambusia, Tex. J. Sci. 42 (1990) 245-256.

[25] Hurlbert S.H., Mulla M.S., Impacts of mosquitofish (Gambusia affinis) predation on plankton communities, Hydrobiologia 83 (1981) 125-151.

[26] Krumholz L.A., Reproduction of the western mosquitofish, Gambusia affinis (Baird and Girard), and its use in mosquito control, Ecol. Monogr. 18 (1948) 1-41.

[27] Linden A.L., Cech J.J., Prey selection by mosquitofish (Gambusia affinis) in California rice fields: effect of vegetation and prey species, J. Am. Mosq. Control Assoc. 6 (1990) 115-120.

[28] Lydeard C., Belk M.C., Management of indigenous fish species impacted by introduced mosquitofish: an experimental approach, Southwest. Nat. 38 (1993) 370-373.

[29] Meffe G.K., Embryo size variation in mosquitofish: optimality vs. plasticity in propagule size, Copeia 1987 (1987) 762-768.

[30] Meffe G.K., Offspring size variation in eastern mosquitofish (Gambusia holbrooki: Poeciliidae) from contrasting thermal environments, Copeia 1990 (1990) 10-18.

[31] Ricker W.E., Computation and interpretation of biological statistics of fish populations, Information Canada, Ottawa, 1975, pp. 8-10.

[32] Rupp H.R., Adverse assessments of Gambusia affinis: an alternative view for mosquito control practitioners, J. Am. Mosq. Control Assoc. 12 (1996) 155-166.

[33] Schaefer J.F., Heulett S.T., Farrell T.M., Interactions between two poeciliid fishes (Gambusia holbrooki and Heterandria formosa) and their prey in a Florida marsh, Copeia 1994 (1994) 516-520.

[34] Thibault R.E., Schultz R.J., Reproductive adaptations among viviparous fishes (Cyprinodontiformes: Poeciliidae), Evolution 32 (1978) 320-333.

[35] Vargas M.J., Sostoa A., Life history of Gambusia holbrooki (Pisces, Poeciliidae) in the Ebro delta (NE Iberian peninsula), Hydrobiologia 341 (1996) 215-224.

[36] Vondracek B., Wurtsbaugh W.A., Cech J.J., Growth and reproduction of the mosquitofish, Gambusia affinis, in relation to temperature and ration level: consequences for life history, Environ. Biol. Fish. 21 (1988) 45-57.

[37] Waters T.F., Secondary production in inland waters, Anim. Ecol. Res. 10 (1977) 91-164.

[38] Wurtsbaugh W., Cech J.J., Compton J., Effect of fish size on prey size selection in Gambusia affinis, Proceedings and papers of the forty-eighth annual Conference of the California Mosquito and Vector Control Association, January 20-23, 1980, pp. 48-51.

[39] Zar J.H., Biostatistical Analysis, 2nd ed., Prentice-Hall International Inc., Englewood Cliffs, New Jersey, 1984, 718 p. 